\title{
HyFlex nickel-titanium rotary instruments after clinical use: metallurgical properties
}

\author{
Y. Shen ${ }^{1}$, J. M. Coil ${ }^{1}$, H. Zhou ${ }^{2}$, Y. Zheng ${ }^{3}$ \& M. Haapasalo ${ }^{1}$ \\ ${ }^{1}$ Division of Endodontics, Department of Oral Biological \& Medical Sciences, Faculty of Dentistry, The University of British \\ Columbia Vancouver, BC, Canada; ${ }^{2}$ Center for Biomedical Materials and Engineering, College of Material Science and Chemical \\ Engineering, Harbin Engineering University, Harbin; and ${ }^{3}$ State Key Laboratory for Turbulence and Complex Systems and \\ Department of Materials Science and Engineering, College of Engineering Peking University Beijing, China
}

\begin{abstract}
Shen Y, Coil JM, Zhou H, Zheng Y, Haapasalo M. HyFlex nickel-titanium rotary instruments after clinical use: metallurgical properties. International Endodontic Journal, 46, 720-729, 2013.
\end{abstract}

Aim To analyse the type and location of defects in HyFlex CM instruments after clinical use in a graduate endodontic programme and to examine the impact of clinical use on their metallurgical properties.

Methodology A total of 468 HyFlex CM instruments discarded from a graduate endodontic programme were collected after use in three teeth. The incidence and type of instrument defects were analysed. The lateral surfaces of the defect instruments were examined by scanning electron microscopy. New and clinically used instruments were examined by differential scanning calorimetry (DSC) and x-ray diffraction (XRD). Vickers hardness was measured with a 200-g load near the flutes for new and clinically used axially sectioned instruments. Data were analysed using one-way ANOVA or Tukey's multiple comparison test.

Results Of the 468 HyFlex instruments collected, no fractures were observed and 16 (3.4\%) revealed deformation. Of all the unwound instruments, size 20, .04 taper unwound the most often $(n=5)$ followed by size $25, .08$ taper $(n=4)$. The trend of DSC plots of new instruments and clinically used (with

Correspondence: Markus Haapasalo, Division of Endodontics, Oral Biological \& Medical Sciences, UBC Faculty of Dentistry, 2199 Wesbrook Mall, Vancouver, BC, Canada V6T $1 \mathrm{Z3}$. (Tel.: +1 604822 5996; fax: +1 604822 3562:

e-mail; markush@dentistry.ubc.ca). and without defects) instruments groups were very similar. The DSC analyses showed that HyFlex instruments had an austenite transformation completion or austenite-finish $\left(\mathrm{A}_{\mathrm{f}}\right)$ temperature exceeding $37^{\circ} \mathrm{C}$. The $A_{f}$ temperatures of HyFlex instruments (with or without defects) after multiple clinical use were much lower than in new instruments $(P<0.05)$. The enthalpy values for the transformation from martensitic to austenitic on deformed instruments were smaller than in the new instruments at the tip region $(P<0.05)$. XRD results showed that NiTi instruments had austenite and martensite structure on both new and used HyFlex instruments at room temperature. No significant difference in microhardness was detected amongst new and used instruments (with and without defects).

Conclusions The risk of HyFlex instruments fracture in the canal is very low when instruments are discarded after three cases of clinical use. New HyFlex instruments were a mixture of martensite and austenite structure at body temperature. Multiple clinical use caused significant changes in the microstructural properties of HyFlex instruments. Smaller instruments should be considered as single-use.

Keywords: clinical, defect, HyFlex CM, instrument, metallurgical property, nickel-titanium.

Received 24 July 2012; accepted 12 December 2012

\section{Introduction}

Nickel-titanium (NiTi) is called an exotic metal because it does not conform to the normal rules of metallurgy. The NiTi alloys used in root canal 
treatment contain approximately 56\% (wt) nickel and 44\% (wt) titanium (Walia et al. 1988). NiTi alloy has special characteristics of superelasticity and shape memory (Thompson 2000). Superelasticity is associated with the occurrence of a phase transformation of the alloy upon application of stress above a critical level, which takes place when the ambient temperature is above the so-called austenite-finish temperature of the material. This stress-induced martensitic transformation reverses spontaneously upon release of the stress; the material then returns to its original shape and size (Saburi 1998). This special property manifests as an enhanced elasticity of the NiTi alloy, allowing the material to recover after large strains. Thus, NiTi instruments appear highly flexible and elastic. Experimental and clinical evidence suggests that the use of NiTi instruments with rotary movement results in improved preparation quality (Peters et al. 2003, Cheung \& Liu 2009). In particular, the incidence of gross preparation errors is greatly reduced.

Clinical use of NiTi instruments can result in fracture of the instrument by cyclic fatigue or torsional stress (Sattapan et al. 2000, Cheung et al. 2005, Parashos \& Messer 2006, Shen et al. 2006, 2009a,b, c,d,e). Fatigue fracture is caused by crack initiation at the surface and transgranular crack growth, which are likely to occur when the instrument is rotating within a curvature (Pruett et al. 1997, Cheung et al. 2005, 2007, Spanaki-Voreadi et al. 2006, Cheung \& Darvell 2007) . Torsional failure is the result of an applied shear moment exceeding the elastic limit of the material, producing plastic deformation and, ultimately, a fracture (Sattapan et al. 2000, Cheung et al. 2005, Shen et al. 2006, Park et al. 2010). This may occur when the tip of the instrument is forced into a narrow canal lumen, generating high torsional loads (Blum et al. 1999, Peters et al. 2003). On the other hand, because of the 'torque control' function of some specially designed electric motors, the instrument may be subjected to repeated, reversing torsional loads and hence risk failure due to torsional fatigue (Berutti et al. 2004, Best et al. 2004). Several strategies have been suggested by manufacturers to reduce the chance of separation of NiTi instruments (Gutmann \& Gao 2012). These methods include (i) modifying the surface of the instrument through processes such as electropolishing (e.g. RaCe; FKG Dentaire, La Chaux-de-Fonds, Switzerland), (ii) reducing the contact area between the instrument and the root canal wall by modifying the instrument's cross-sectional geometry and taper (e.g. FlexMaster, VDW, Munich, Germany; ProTaper, Dentsply Maillefer, Ballaiges, Switzerland) and (iii) improvement in the manufacturing process that provide superior mechanical properties (e.g. Twisted Files; SybronEndo, Orange, CA, USA). Recently, a series of proprietary thermomechanical processing procedures have been used to optimize the structure of the NiTi wire blanks for rotary instruments (Gutmann \& Gao 2012, Shen et al. 2012a). Vortex files are manufactured from M-Wire, which had undergone a proprietary method of treatment. One study (Shen et al. 2012 b) found that clinical single-use had no evident effect on phase transformation of the Vortex files. Controlled Memory Wire (CM Wire; DS Dental, Johnson City, TN, USA), which is also a novel NiTi alloy with flexible properties, was introduced in 2010. CM NiTi files are flexible and have high resistance to cyclic fatigue (Shen et al. 2011a, 2012a,b) and normal torsional strength (Peters et al. 2012). HyFlex CM (Coltene Whaledent, Cuyahoga Falls, OH, USA) instruments are made from CM Wire. Several important physical properties of HyFlex instruments have been tested (Zinelis et al. 2010, Testarelli et al. 2011, Peters et al. 2012). The safety of NiTi instruments for clinical use requires an understanding of the basic mechanism involved in the development of NiTi defects. Therefore, the purpose of this study was to analyse the type and location of defects for HyFlex instruments after clinical use in a graduate endodontic programme and to examine the impact of clinical use on metallurgical properties of the files.

\section{Materials and methods}

HyFlex CM instruments were adopted for use by residents in a graduate endodontic programme at the Faculty of Dentistry, University of British Columbia, Vancouver, Canada, from September 2011 to May 2012. During the period of this study, a total of nine residents participated. Eightythree per cent of the treated teeth were molars and $27 \%$ were premolars. The residents had a free choice of instrument type of several different brands of rotary files available in the programme, but when Hyflex files were used, no other rotary files were used in the same tooth. Each set of HyFlex instruments was limited to use on three clinical cases. Instruments that had been used in very 
complex, severely curved or calcified canals were discarded immediately.

\section{Instrumentation technique}

Canal preparation was performed according to the manufacturer's recommendations. After the access cavity was prepared, the canal was negotiated to the working length with stainless steel hand files up to size 15. In the order of clinical use, each set of HyFlex instruments included the following sizes 25, .08 taper; size 20, .04 taper; size 25, .04 taper; size 20, .06 taper and size 30, .04 taper; further enlargement with the size 40/.04 was performed only when necessary. Rotary files were used in an electric motor (ATR Tecnika, Milan, Italy) with a 16:1 reduction handpiece (W\&H, Burmoos, Austria) at a setting and speed recommended by the manufacturer (at $500 \mathrm{rpm}$ ). To eliminate bacteria, pulp tissue and accumulation of debris, approximately $1 \mathrm{~mL}$ of $3 \%$ sodium hypochlorite was used as an irrigant between file sizes. After instrumentation, the canal was irrigated with QMiX (Dentsply; Tulsa Dental Specialties, Tulsa, OK, USA) to remove smear layer and kill residual bacteria. Instruments were discarded when they had reached the designated number of uses (three) or when they were worn, fractured or when found to have any other discernible defects.

\section{Collection and examination of discarded instruments}

A total of 468 HyFlex instruments were discarded after routine clinical use. Before clinical use, these instruments were examined under a stereomicroscope (Microdissection; Zeiss, Bernried, Germany) at $10 \times$ magnification. All discarded instruments were ultrasonically cleaned in Empower solution (Metrex, Orange, CA, USA) for $15 \mathrm{~min}$, autoclaved $\left(132{ }^{\circ} \mathrm{C}\right.$ for $5 \mathrm{~min}$ ) and then examined by one investigator under a stereomicroscope.

Any defects with unwinding were noted and classified into one of the following categories: (i) intact instruments, (ii) instruments with unwinding, (iii) instruments with unwinding and twisting, and (iv) fractured instruments. The location of defect was determined by measuring the length between the instrument tip and the beginning, as well as the end, of the unwound region (Cheung et al. 2007) using a light microscope. All defect instruments were cleaned in an ultrasonic bath in absolute alcohol for $90 \mathrm{~s}$ and examined in lat- eral view using a scanning electron microscope at a magnification of $20-700 \times$ operating at $8 \mathrm{kV}$ (Stereoscan 260; Cambridge Instruments, Cambridge, UK).

\section{Differential scanning calorimetry}

Differential scanning calorimetry analyses were first performed on representative new and clinically used HyFlex instruments. Test specimens included three groups: (i) new instruments including as-recevied condition without autoclaving and after two autoclave cycles, (ii) clinically used instruments without unwinding, and (iii) clinically used instruments that had a unwinding after use. Ten specimens for each group were subjected to this test. Each specimen consisted of two segments, 4-5 $\mathrm{mm}$ in length and cut from the instruments using a slow-speed water-cooled diamond saw. Each file had two different parts for the differential scanning calorimetry (DSC) test, including apical part (from tip to D6) and coronal part (from D7-D11). The DSC analyses were conducted (PYRIS, Perkin Elmer Diamond Series DSC; PerkinElmer, Shelton, CT, USA) over a temperature ranging from $-100{ }^{\circ} \mathrm{C}$ to $100{ }^{\circ} \mathrm{C}$ using the liquid nitrogen cooling accessory to achieve subambient temperatures. For each analysis, the specimen was first heated from room temperature to $100^{\circ}$, then cooled from $100{ }^{\circ} \mathrm{C}$ to $-100{ }^{\circ} \mathrm{C}$ to obtain the cooling DSC curve and subsequently heated from $-100{ }^{\circ} \mathrm{C}$ back to $100{ }^{\circ} \mathrm{C}$ to obtain the heating DSC curve. The linear heating or cooling rate was a standard $10{ }^{\circ} \mathrm{C} \mathrm{min}^{-1}$, and during each analysis, the DSC cell was purged with nitrogen at a rate of

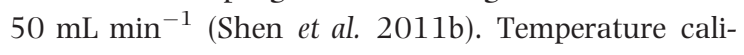
bration of the DSC apparatus was performed with indium under the experimental condition. The plots were analysed by PYRIS computer software (PerkinElmer Inc) to obtain the onset temperatures for the phase transformations, along with the enthalpy changes $(\Delta \mathrm{H})$ associated with these processes. The transformation temperatures were obtained from the intersection between extrapolation of the baseline and maximum gradient line of the lambda-type DSC curve (Yahata et al. 2009, Hou et al. 2011). The martensitic transformation-starting and transformation-finishing points $\left(\mathrm{Ms}, \mathrm{M}_{\mathrm{f}}\right.$ ) and reverse transformation-starting and transformation-finishing points $\left(\mathrm{As}, \mathrm{A}_{\mathrm{f}}\right.$ ) were determined.

\section{X-ray diffraction}

X-ray diffraction (X'Pert PRO; PANalytical BV, Almelo, the Netherlands) analyses were performed (Alapati 
et al. 2009b, Shen et al. 2011b) on new instruments and clinically used instruments without defect. Analyses were performed on five samples each at room temperature $\left(25^{\circ} \mathrm{C}\right)$, with $\mathrm{CuK} \alpha$ monochromatic radiation at $40 \mathrm{kV}$ and tube current of $100 \mathrm{~mA}$. Segments from the shank portions of NiTi instruments were cut from the file using a low-speed, water-cooled diamond saw. Multiple segments were then adhered together and ground using 2000\# SiC sandpaper to obtain a plane. Then, the segments were cleaned by acetone and distilled water and placed side-by-side on the glass sample holder with an area of approximately $8 \times 8 \mathrm{~mm}^{2}$. Segments from the shank portions of NiTi files were cut into approximately $8 \mathrm{~mm}$ lengths using a low-speed, water-cooled diamond saw. Multiple segments yielding approximately $8 \times 8 \mathrm{~mm}$ lengths were the test samples and were placed side-by-side on the glass sample holder. The x-ray diffraction (XRD) peaks were identified using the pattern library Powder Diffraction File (PDF release 2004, International Centre for Diffraction Data, Newtown Square, PA, USA) by the software MDI Jade5.0 (Materials Data, Inc., Livermore, CA, USA).

\section{Vickers microhardness}

An apical segment of $6-7 \mathrm{~mm}$ in length was cut with a water-cooled diamond saw from instruments selected for the Vickers microhardness test. Test specimens included three groups: (i) new instruments, (ii) clinically used instruments without defect and (iii) clinically used instruments that had a defect after use. These segments were mounted and polished by using standard metallographic preparation techniques (ASTM 2007). Vickers microhardness measurements were performed at ambient temperature with a $200 \mathrm{~g}$ load and $15 \mathrm{~s}$ dwell time (MicroMet microhardness tester; Buehler Ltd, Lake Bluff, IL, USA). Three specimens for each group were subjected to the test.
Five microindentations were made for each instrument.

The data for DSC and microhardness were analysed statistically using one-way ANOVA, and comparison of means was conducted using the Tukey's multiple comparison test (SPSS for Windows 11.0; SPSS, Chicago, IL, USA), when necessary, at a significance level of $P<0.05$.

\section{Results}

Of the 468 HyFlex instruments collected, no fractures were observed but 16 (3.4\%) revealed some form of deformation along the working part of the instrument (Table 1). The majority (14 of 16) of the deformed instruments showed unwinding, whilst only 2 of 16 $(0.4 \%)$ showed both twisting and unwinding on the same instrument (Fig. 1). Of all the unwound instruments, size 20, .04 taper unwound the most often $(n=5)$ followed by size $25, .08$ taper $(n=4)$. The location of (the beginning of) defects was $0.81 \pm 0.34 \mathrm{~mm}$ from the tip, and the length of the unwound region was $1.68 \pm 0.6 \mathrm{~mm}$. Many of the deformed areas showed the presence of cracks running in the general direction of the machining grooves and often involved the cutting edge of the instrument (Fig. 1b,d).

Figure 2 displays DSC plots for both the heating and cooling cycles of different instrument groups (unused, used without unwinding and used with unwinding). The trend of DSC plots of the three groups is very similar. The DSC curve for apical part of instrument exhibits lower peak than coronal part on both cooling and heating. There are a few peaks on the cooling cycle of HyFlex instruments, indicating multistage phase transformation. The $\mathrm{A}_{\mathrm{f}}$ temperatures of new instrument group $\left(50{ }^{\circ} \mathrm{C}\right)$ was significant higher than used groups $\left(31.4-33.6^{\circ} \mathrm{C}\right)(P<0.05$;

Table 1 The number of discarded HyFlex instruments showing defects (\% of Total No. of instruments)

\begin{tabular}{|c|c|c|c|c|c|c|c|}
\hline \multirow[b]{2}{*}{ HyFlex } & \multirow[b]{2}{*}{$N$} & \multirow[b]{2}{*}{ Fracture } & \multicolumn{5}{|c|}{ Deformation } \\
\hline & & & $\begin{array}{l}\text { Unwinding } \\
\text { (\% of total no.) }\end{array}$ & $\begin{array}{l}\text { Unwinding } \\
\text { and twisting } \\
\text { (\% of total no.) }\end{array}$ & $\begin{array}{c}\text { Subtotal } \\
\text { (\% of total no.) }\end{array}$ & $\begin{array}{l}\text { Start from tip to } \\
\text { the location of unwinding } \\
\text { (mean } \pm S D ; \mathrm{mm})\end{array}$ & $\begin{array}{l}\text { Length of the } \\
\text { unwound region } \\
\text { (mean } \pm \mathrm{SD} ; \mathrm{mm} \text { ) }\end{array}$ \\
\hline $25 / .08$ & 77 & 0 & $4(5.2)$ & 0 & $4(5.2)$ & $0.73 \pm 0.26$ & $2.10 \pm 0.84$ \\
\hline $20 / .04$ & 80 & 0 & $5(6.3)$ & 0 & $5(6.3)$ & $0.84 \pm 0.55$ & $1.32 \pm 0.52$ \\
\hline $25 / .04$ & 79 & 0 & $3(3.8)$ & 0 & $3(3.8)$ & $0.97 \pm 0.15$ & $1.60 \pm 0.46$ \\
\hline $20 / .06$ & 78 & 0 & 0 & $1(1.3)$ & $1(1.3)$ & 0.50 & 1.80 \\
\hline $30 / .04$ & 78 & 0 & $2(2.6)$ & $1(1.3)$ & $3(3.9)$ & $0.80 \pm 0.20$ & $1.77 \pm 0.47$ \\
\hline $40 / .04$ & 76 & 0 & 0 & 0 & 0 & 0 & 0 \\
\hline Total & 468 & 0 & $14(3.0)$ & $2(0.4)$ & $16(3.4)$ & $0.81 \pm 0.34$ & $1.68 \pm 0.60$ \\
\hline
\end{tabular}



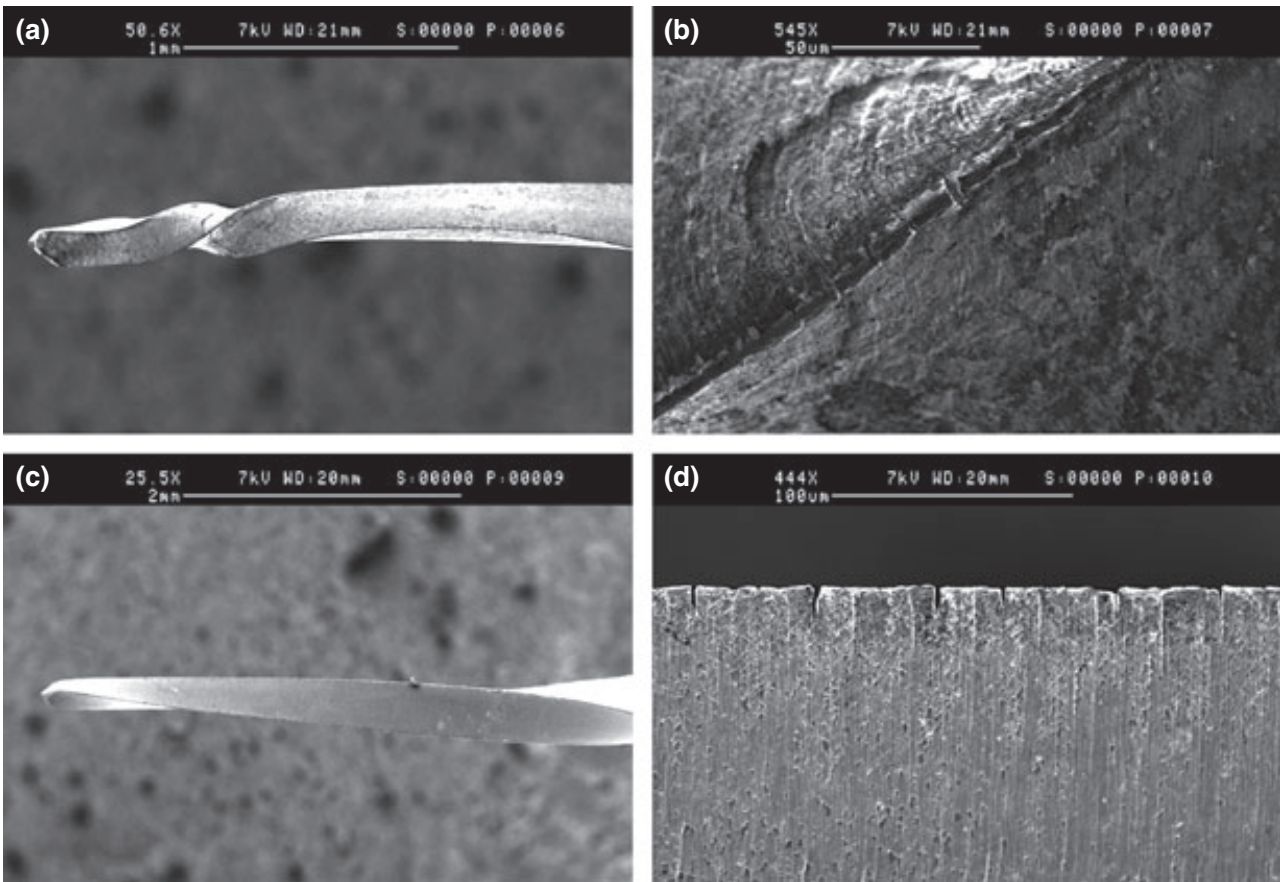

Figure 1 Longitudinal examination of unwound HyFlex instruments. (a) Deformation around the spiralled sector in an unwound and twisted instrument. (b) A higher magnification view of the specimen in (a) showing twisted region. (c) An unwound instrument. (d) A higher magnification of the specimen in (c) shows cracking perpendicular to the file axis.

Table 2). There was no significant difference on $A_{f}$ temperatures between instruments with and without defect after clinical use $(P>0.05)$. The enthalpy values for the transformation from martensitic to austenitic on the new instruments were higher than on the used and deformed instruments, although there was no statistical difference. The enthalpy values for the transformation from martensitic to austenitic at the file tip segment were smaller in deformed instruments than in unused instruments $(P<0.05)$. The DSC results were very similar for new instruments between without autoclaving and after autoclaving.

X-ray diffraction patterns at $25{ }^{\circ} \mathrm{C}$ in HyFlex new

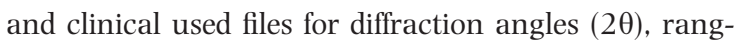
ing from $20-100^{\circ}$. The two HyFlex instruments that were used first during the rotary preparation, size 25 , .08 taper and 20, .04 taper had more unwinding (4 and 5, respectively) than other file sizes. Their XRD profile contained three major peaks for the (110), (200) and (211) atomic planes in austenite. The major peak for the (110) austenite atomic plane was clear. The XRD profile also contained numerous peaks (111) and (121) that could be indexed to atomic planes of martensite (Fig. 3).

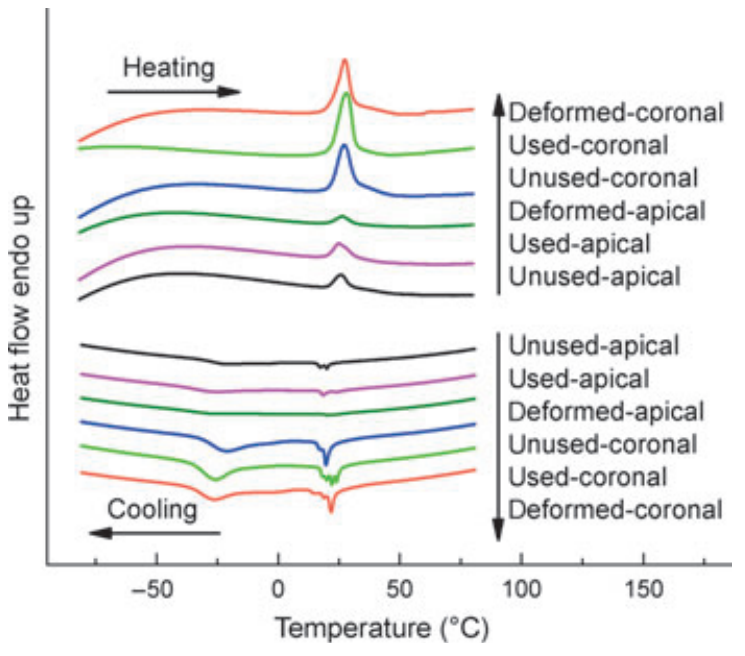

Figure 2 Differential scanning calorimetry of unused and used HyFlex instruments.

The Vickers microhardness values of new instruments, clinically used instruments without defect and used instruments with defect were $315.1 \pm 27.6$, $339.1 \pm 26.2$ and $342.1 \pm 27.6$, respectively. There was no difference of mean microhardness amongst 
Table 2 Phase transformation temperatures and associated energy of HyFlex files after three times clinical use

\begin{tabular}{|c|c|c|c|c|c|c|}
\hline & \multicolumn{3}{|c|}{ Heating } & \multicolumn{3}{|c|}{ Cooling } \\
\hline & $\mathrm{A}_{\mathrm{s}}\left({ }^{\circ} \mathrm{C}\right)$ & $\mathrm{A}_{\mathrm{f}}\left({ }^{\circ} \mathrm{C}\right)$ & $\Delta \mathrm{H}\left(\mathrm{J} \mathrm{g}^{-1}\right)$ & $\mathrm{M}_{\mathrm{s}}\left({ }^{\circ} \mathrm{C}\right)$ & $\mathrm{M}_{\mathrm{f}}\left({ }^{\circ} \mathrm{C}\right)$ & $\Delta \mathrm{H}\left(\mathrm{J} \mathrm{g}^{-1}\right)$ \\
\hline Unused apical & $20.1 \pm 0.18$ & $51.4 \pm 0.30^{\mathrm{a}}$ & $13.2 \pm 0.52^{c}$ & $21.6 \pm 0.52$ & $-30.7 \pm 1.57$ & $-8.6 \pm 1.07$ \\
\hline Unused coronal & $21.2 \pm 0.25$ & $47.0 \pm 0.47^{\mathrm{a}}$ & $16.2 \pm 0.07$ & $22.6 \pm 0.14$ & $-31.9 \pm 0.13$ & $-10.6 \pm 0.18$ \\
\hline Used apical & $20.2 \pm 0.01$ & $33.3 \pm 0.79^{b}$ & $9.4 \pm 0.88^{\mathrm{c}, \mathrm{d}}$ & $29.5 \pm 1.60$ & $-38.5 \pm 2.26$ & $-3.3 \pm 0.45$ \\
\hline Used coronal & $21.7 \pm 0.09$ & $32.2 \pm 0.17^{\mathrm{b}}$ & $16.7 \pm 0.01$ & $26.1 \pm 0.08$ & $-35.5 \pm 0.04$ & $-11.5 \pm 0.75$ \\
\hline Deformed apical & $20.8 \pm 0.10$ & $33.6 \pm 0.08^{b}$ & $8.1 \pm 0.30^{d}$ & $28.5 \pm 1.63$ & $-38.7 \pm 0.66$ & $-5.6 \pm 0.57$ \\
\hline Deformed coronal & $20.5 \pm 0.47$ & $31.4 \pm 0.03^{b}$ & $15.9 \pm 0.38$ & $23.9 \pm 0.52$ & $-36.6 \pm 0.42$ & $-9.5 \pm 0.37$ \\
\hline
\end{tabular}

Different superscript letters indicate statistically significant differences between groups $(P<0.05)$.

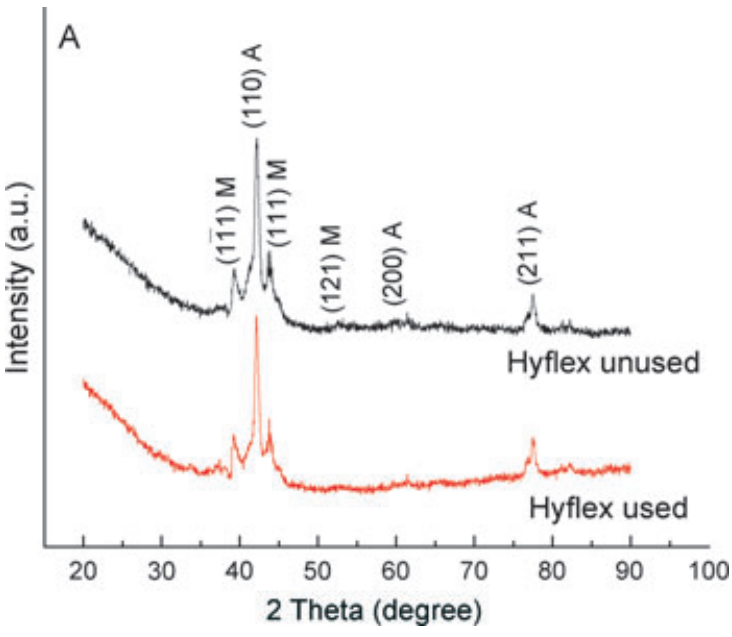

Figure 3 X-ray diffraction of unused and used HyFlex instruments.

new, without defect and with defect instruments groups $(P>0.05)$.

\section{Discussion}

With novel NiTi endodontic instruments being successively developed and commercialized by manufacturers, it has become important for clinicians to understand clinical guidelines for and material properties of NiTi instruments. Clinical studies can provide detailed and reliable information about how and why defects occur. Metallurgical tests could contribute to better understanding of the mechanism of defects on NiTi instruments. The HyFlex instruments investigated were made from a special NiTi alloy that has been claimed to have a lower per cent in weight of nickel (52\%) (Testarelli et al. 2011) and subjected to proprietary thermomechanical processing. In the present study, no fractures (of 468 instruments) occurred after clinical use in three teeth, and in only some occasions, plastic deformation (16 of 468) was detected. Reasons for the fracture of NiTi instruments may be complex and multifactorial (Kuhn et al. 2001, Parashos \& Messer 2006, Shen et al. 2009a, -e, Condorelli et al. 2010); some important ones may be operator-related, such as skill, experience, instrumentation technique and the bulk material properties.

Unexpected instrument fracture has been recognized as a potential risk of NiTi instruments during clinical use. The incidence of instrument fracture in clinical practice for instruments used multiple times has varied from $0.39 \%$ to $21 \%$ (Sattapan et al. 2000, Parashos et al. 2004, Peng et al. 2005, Alapati et al. 2005, Di Fiore et al. 2006, Shen et al. 2006, 2009b). Although fractured instruments may not compromise the outcome if the treatment is performed to a high standard (Spili et al. 2005), the retained file fragments may impede microbial control beyond the obstruction. Moreover, excessive removal of tooth structure in an attempt to retrieve the instrument fragment may be associated with root perforation and reduced root strength (Souter \& Messer 2005). Possible strategies to increase safety of NiTi rotary instruments include an improvement in the manufacturing process or the use of new alloys that provide superior mechanical properties. Thermal treatment of NiTi alloys for endodontic use is a new field of research, and little information is currently available. Thermal treatment of the alloy is known to produce a better arrangement of the crystal structure and changes in the percentage of phases of the alloy, thus leading to improved flexibility and mechanical behaviour. In the current study, the $A_{f}$ of new HyFlex instruments was over $47^{\circ} \mathrm{C}$. This indicated that HyFlex instruments were a mixture of martensite and austenite structure at body temperature.

The martensitic phase of NiTi has some unique properties that have made it an ideal material for many applications (Davis 2000). The martensitic phase transformation has excellent damping characteristics 
because of the energy absorption characteristics of its twinned phase structure. In addition, the martensitic form of NiTi has remarkable fatigue resistance. According to the manufacturer (ColteneEndo 2012a,b), HyFlex may be up to $300 \%$ more fatigueresistant, compared with other brands of rotary NiTi instruments. Recently, Peters et al. (2012) showed that fatigue resistance of HyFlex is much higher than other rotary instruments tested previously under similar conditions. Other NiTi instruments [TYPHOON Infinite Flex; TYP (Clinician's Choice Dental Products, New Milford, CT, USA)] are also made from CM Wire. Two previous studies (Shen et al. 2011a,b, 2012a) found that TYP CM instruments yielded a 3 to 9 times longer fatigue life than conventional NiTi instruments with the same design when tested dry or in various liquids. Interestingly, HyFlex rotary instruments, which had high fatigue resistance, demonstrated similar torsional resistance as instruments made of conventional NiTi (Peters et al. 2012). Therefore, it was perhaps not surprising that there were no instrument fractures seen in the present study even after clinical use in three teeth. It seems that HyFlex instruments are subjected to a proprietary manufacturing process, which contributes to the safety of the endodontic treatment. However, instrument fracture is a complex, multifactorial event, and many factors (Parashos et al. 2004) such as the operator, root canal anatomy and instrument properties influence the fracture risk.

The mechanical behaviour of NiTi shape memory metal alloy is determined by the relative proportions and characteristics of the microstructural phases. From the point of view of practical applications, NiTi can have three different forms: martensite, stressinduced martensite (superelastic) and austenite. The different crystal structures observed in NiTi alloys impart different properties. When the material is in its martensite form, it is soft and ductile and can be easily deformed. Superelastic NiTi is highly elastic, whilst austenitic NiTi is quite strong and hard (Otsuka \& Wayman 1998). For instance, the martensite phase is less stiff and more pliable, possessing an elastic modulus of 31 to $35 \mathrm{GPa}$ compared with 84 to $98 \mathrm{GPa}$ for austenite (Kusy 1997). A previous study showed that HyFlex instruments are bendable and very flexible (Testarelli et al. 2011). Peters et al. (2012) reported that of 60 HyFlex instruments 49 underwent plastic deformation when used for the preparation of simulated canals in plastic blocks. In the present study of HyFlex instruments during root canal preparation in natural teeth, plastic deformation was much less common. However, based on both studies, it can be conjectured that plastic deformation of HyFlex file can be a useful warning signal as such files are more likely to be discarded before separation during clinical use.

The analytical techniques of XRD and DSC provided complementary information regarding the metallurgical structure of the NiTi instrument. Although XRD analysis is a useful method to investigate the structure of NiTi phases at specific positions (Thayer et al. 1995), this technique only reveals the structure within approximately $50 \mu \mathrm{m}$ of the surface, whereas DSC provides information for the overall bulk specimen and the effects of temperature changes on the phase transformations (Brantley et al. 2002a, Alapati et al. 2009a \& b, Shen et al. 2011b). A potentially important practical result from this study has been observation that multiple clinical uses of HyFlex instruments reduced the $A_{f}$ temperature below the body temperature. The results showed that multiple clinical uses caused significant changes in the microstructural properties of HyFlex instruments. The enthalpy changes for the transformation from martensitic to austenitic on the tip region were greater than on the coronal region of the new HyFlex instruments. This may be partly explained by greater work hardening near the tip region of the instruments during the manufacturing process. It is also possible that the majority of rotary NiTi instruments experience the greatest mechanical stress near the tip segment during instrumentation. Conventional DSC analyses also showed that simulated clinical use can appear to have effects on the NiTi phase transformations for the tip segments of conventional superelastic NiTi instruments that experienced active stress, although the superelastic character of the NiTi alloy is retained (Brantley et al. 2002b). Therefore, it was not surprising that the low enthalpy changes for the transformation from martensitic to austenitic on the tip region occurred in clinically used HyFlex instruments (with and without defects). To obtain more precise information of the effect of clinical use on NiTi instrument with a mixture of martensite and austenite structure, the mechanical properties of clinical used instruments requires further study.

The instrumentation technique can influence the magnitude of stress concentration (Blum et al. 1999, Berutti et al. 2003, Xu \& Zheng 2006). It is accepted that the provision of a glide path facilitates the work of subsequent instruments, which can smoothly clean 
and shape root canals. Enlarging the canal to a size of 15 or 20 before using the rotary NiTi instrument helps to reduce the torsional stress experienced by the instrument (Sattapan et al. 2000) and lower the risk of shear fracture. HyFlex's manufacturer recommended a single-length technique (ColteneEndo 2012a), combined with a coronal flare. The flaring instrument, size 25, .08 taper should not be taken deep into a root canal so as to avoid working the canal wall with the tip. Once coronal enlargement is achieved, size 20, .04 taper instruments are then used to reach the working length. Torque test study (Peters et al. 2012) found that single-length HyFlex technique resulted in overall significantly higher torque values compared with a crown-down approach and, perhaps not unexpectedly, higher axial forces for the small instruments going to working length. In the present study, the two-first clinically used small instruments (size 25, .08 taper and size 20, .04 taper) were deformed more often than any other files. The instruments of martensite phase can be easily deformed, yet they will recover their shape on heating above the transformation temperatures. The manufacturer of HyFlex instruments states that sterilization will result in the instrument regaining its shape (ColteneEndo 2012b). Peters et al. (2012) found that more than half of instruments that underwent plastic deformation in simulated use in plastic block canals recovered their original shape during a sterilization cycle. However, in particular, the small instruments were often permanently deformed. Previous studies (Shen et al. 2006 , 2009c) also confirmed this trend towards a high incidence of instrument distortion in smaller conventional superelastic NiTi instruments. Given the same torque, smaller instruments would be more susceptible to torsional failure than larger instruments. Therefore, caution should be exercised regarding reuse of small HyFlex rotary instruments. The new endodontic NiTi instruments manufactured with the thermomechanical treatment of NiTi wires have greater flexibility than similar instruments made of conventional SE wires (Hou et al. 2011, Testarelli et al. 2011, Gao et al. 2012). Dentists may need to apply less apical pressure against canal walls than with conventional SE NiTi files of the same size and taper.

\section{Conclusion}

None of the 468 HyFlex instruments fractured during instrumentation of three teeth by each file. Only 3.4\% (16 of 468) of the instruments revealed plastic defor- mation. New HyFlex instruments were a mixture of martensite and austenite structure. Multiple clinical uses cause significant changes in the microstructural phases of HyFlex instruments. The $A_{f}$ temperatures of HyFlex instruments after clinical use were below the body temperature. The enthalpy values for the transformation from martensitic to austenitic on the instrument apical regions were smaller in deformed instruments than in unused instruments. This difference was attributed to variations in local stress on the tip region during instrumentation. Smaller instruments should be considered as single-use.

\section{Acknowledgements}

This manuscript was partly supported by Start-up funds, Faculty of Dentistry, University of British Columbia, Canada. The authors thank Shauna Catalano, Lois Bermudez and Franciso Briseno who collected the used NiTi instruments for this study. The authors deny any conflicts of interest.

\section{References}

Alapati SB, Brantley WA, Svec TA, Powers JM, Nusstein JM, Daehn GS (2005) SEM observations of nickel-titanium rotary endodontic instruments that fractured during clinical Use. Journal of Endodontics 31, 40-3.

Alapati SB, Brantley WA, Iijima M et al. (2009a) Metallurgical characterization of a new nickel-titanium wire for rotary endodontic instruments. Journal of Endodontics $\mathbf{3 5}$, 1589-93.

Alapati SB, Brantley WA, Iijima M et al. (2009b) Micro-XRD and temperature-modulated DSC investigation of nickeltitanium rotary endodontic instruments. Dental Materials 25, 1221-9.

ASTM E3-11 (2007) The American Society for Testing and Materials (ASTM): Standard Guide for Preparation of Metallographic Specimens. West Conshohocken, PA: American Society for Testing and Materials.

Berutti E, Chiandussi G, Gaviglio I, Ibba A (2003) Comparative analysis of torsional and bending stresses in two mathematical models of nickel-titanium rotary instruments: ProTaper versus ProFile. Journal of Endodontics 29, $15-9$.

Berutti E, Negro AR, Lendini M, Pasqualini D (2004) Influence of manual preflaring and torque on the failure rate of ProTaper rotary instruments. Journal of Endodontic 30, 228-30.

Best S, Watson P, Pilliar R, Kulkarni GG, Yared G (2004) Torsional fatigue and endurance limit of a size 30.06 ProFile rotary instrument. International Endodontic Journal 37, $370-3$. 
Blum JY, Cohen A, Machtou P, Micallef JP (1999) Analysis of forces developed during mechanical preparation of extracted teeth using Profile NiTi rotary instruments. International Endodontic Journal 32, 24-31.

Brantley WA, Svec TA, Iijima M, Powers JM, Grentzer TH (2002a) Differential scanning calorimetric studies of nickel-titanium rotary endodontic instruments. Journal of Endodontics 28, 567-72.

Brantley WA, Svec TA, Iijima M, Powers JM, Grentzer TH (2002b) Differential scanning calorimetric studies of nickel-titanium rotary endodontic instruments after simulated clinical use. Journal of Endodontics 28, 774-8.

Cheung GS, Darvell BW (2007) Fatigue testing of a NiTi rotary instrument. Part 2: fractographic analysis. International Endodontic Journal 40, 619-25.

Cheung GS, Liu CS (2009) A retrospective study of endodontic treatment outcome between nickel-titanium rotary and stainless steel hand filing techniques. Journal of Endodontics 35, 938-43.

Cheung GS, Peng B, Bian Z, Shen Y, Darvell BW (2005) Defects in ProTaper S1 instruments after clinical use: fractographic examination. International Endodontic Journal 38, 802-9.

Cheung GS, Bian Z, Shen Y, Peng B, Darvell BW (2007) Comparison of defects in ProTaper hand-operated and engine-driven instruments after clinical use. International Endodontic Journal 40, 167-78.

ColteneEndo (2012a) File sequence step by step card. Available at: http://hyflex.com/DevDownloads/StepByStep_Extended. pdf [accessed 2 February 2012].

ColteneEndo (2012b) HyflexCM Brochure. Available at: http://www.hyflexcm.com/DevDownloads/HyflexCM_brochure. pdf [accessed 2 February 2012].

Condorelli GG, Bonaccorso A, Smecca E, Schäfer E, Cantatore G, Tripi TR (2010) Improvement of the fatigue resistance of NiTi endodontic files by surface and bulk modifications. International Endodontic Journal 43, 866-73.

Davis JR (2000) ASM Specialty Handbook: Nickel, Cobalt, and Their Alloys. Materials Park, OH: ASM International.

Di Fiore PM, Genov KA, Komaroff E, Li Y, Lin L (2006) Nickel-titanium rotary instrument fracture: a clinical practice assessment. International Endodontic Journal 39, 700-8.

Gao Y, Gutmann JL, Wilkinson K, Maxwell R, Ammon D (2012) Evaluation of the impact of raw materials on the fatigue and mechanical properties of ProFile Vortex rotary instruments. Journal of Endodontics 38, 398-401.

Gutmann JL, Gao Y (2012) Alteration in the inherent metallic and surface properties of nickel-titanium root canal instruments to enhance performance, durability and safety: a focused review. International Endodontic Journal 45, 113-28.

Hou X, Yahata Y, Hayashi Y, Ebihara A, Hanawa T, Suda H (2011) Phase transformation behaviour and bending property of twisted nickel-titanium endodontic instruments. International Endodontic Journal 44, 253-8.
Kuhn G, Tavernier B, Jordan L (2001) Influence of structure on nickel-titanium endodontic instruments failure. Journal of Endodontics 27, 516-20.

Kusy RP (1997) A review of contemporary archwires: their properties and characteristics. Angle Orthodontist 67, 197-207.

Otsuka K, Wayman CM (1998) Shape Memory Materials. New York: Cambridge University Press.

Parashos P, Messer HH (2006) Rotary NiTi instrument fracture and its consequences. Journal of Endodontics 32, 1031-43.

Parashos P, Gordon I, Messer HH (2004) Factors influencing defects of rotary nickel-titanium endodontic instruments after clinical use. Journal of Endodontics 30, 722-5.

Park SY, Cheung GS, Yum J, Hur B, Park JK, Kim HC (2010) Dynamic torsional resistance of nickel-titanium rotary instruments. Journal of Endodontics 36, 1200-4.

Peng B, Shen Y, Cheung GS, Xia TJ (2005) Defects in ProTaper S1 instruments after clinical use: longitudinal examination. International Endodontic Journal 38, 550-7.

Peters OA, Peters CI, Schönenberger K, Barbakow F (2003) ProTaper rotary root canal preparation: assessment of torque and force in relation to canal anatomy. International Endodontic Journal 36, 93-9.

Peters OA, Gluskin AK, Weiss RA, Han JT (2012) An in vitro assessment of the physical properties of novel Hyflex nickel-titanium rotary instruments. International Endodontic Journal 45, 1027-34.

Pruett JP, Clement DJ, Carnes DL Jr (1997) Cyclic fatigue testing of nickel-titanium endodontic instruments. Journal of Endodontics 23, 77-85.

Saburi T (1998) Ti-Ni shape memory alloys. In: Otsuka K, Wayman CM, eds. Shape Memory Materials. Cambridge, UK: Cambridge University Press, pp. 49-96.

Sattapan B, Nervo GJ, Palamara JE, Messer HH (2000) Defects in rotary nickel-titanium files after clinical use. Journal of Endodontics 26, 161-5.

Shen Y, Cheung GS, Bian Z, Peng B (2006) Comparison of defects in ProFile and ProTaper systems after clinical use. Journal of Endodontics 32, 61-5.

Shen Y, Haapasalo M, Cheung GS, Peng B (2009a) Defects in nickel-titanium instruments after clinical use. Part 1: relationship between observed imperfections and factors leading to such defects in a cohort study. Journal of Endodontics 35, 129-32.

Shen Y, Cheung GS, Peng B, Haapasalo M (2009b) Defects in nickel-titanium instruments after clinical use. Part 2: fractographic analysis of fractured surface in a cohort study. Journal of Endodontics 35, 133-6.

Shen Y, Coil JM, Haapasalo M (2009c) Defects in nickeltitanium instruments after clinical use. Part 3: a 4-year retrospective study from an undergraduate clinic. Journal of Endodontics 35, 193-6.

Shen Y, Winestock E, Cheung GS, Haapasalo M (2009d) Defects in nickel-titanium instruments after clinical use. 
Part 4: an electropolished instrument. Journal of Endodontics 35, 197-201.

Shen Y, Coil JM, McLean AG, Hemerling DL, Haapasalo M (2009e) Defects in nickel-titanium instruments after clinical use. Part 5: single use from endodontic specialty practices. Journal of Endodontics 35, 1363-7.

Shen Y, Qian W, Abtin H, Gao Y, Haapasalo M (2011a) Fatigue testing of controlled memory wire nickel-titanium rotary instruments. Journal of Endodontics 37, 997-1001.

Shen Y, Zhou HM, Zheng YF, Campbell L, Peng B, Haapasalo M (2011b) Metallurgical characterization of controlled memory wire nickel-titanium rotary instruments. Journal of Endodontics 37, 1566-71.

Shen Y, Qian W, Abtin H, Gao Y, Haapasalo M (2012a) Effect of environment on fatigue failure of controlled memory wire nickel-titanium rotary instruments. Journal of Endodontics 38, 376-80.

Shen Y, Coil JM, Zhou HM, Tam E, Zheng YF, Haapasalo M (2012b) ProFile Vortex instruments after clinical use: a metallurgical properties study. Journal of Endodontics 38, 1613-7.

Souter N, Messer HH (2005) Complications associated with fractured file removal using an ultrasonic technique. Journal of Endodontics 31, 450-2.

Spanaki-Voreadi AP, Kerezoudis NP, Zinelis S (2006) Failure mechanism of ProTaper Ni-Ti rotary instruments during clinical use: fractographic analysis. International Endodontic Journal 39, 171-8.
Spili P, Parashos P, Messer HH (2005) The impact of instrument fracture on outcome of endodontic treatment. Journal of Endodontics 31, 845-50.

Testarelli L, Plotino G, Al-Sudani D et al. (2011) Bending properties of a new nickel-titanium alloy with a lower percent by weight of nickel. Journal of Endodontics 37, 1293-5.

Thayer TA, Bagby MD, Moore RN, DeAngelis RJ (1995) X-ray diffraction of nitinol orthodontic arch wires. American Journal of Orthodontics and Dentofacial Orthopedics 107, 604-12.

Thompson SA (2000) An overview of nickel-titanium alloys used in dentistry. International Endodontic Journal 33, 297-310.

Walia H, Brantley WA, Gerstein H (1988) An initial investigation of the bending and torsional properties of nitinol root canal files. Journal of Endodontics 14, 346-51.

$\mathrm{Xu} \mathrm{X}$, Zheng Y (2006) Comparative study of torsional and bending properties for six models of nickel-titanium root canal instruments with different cross-sections. Journal of Endodontics 32, 372-5.

Yahata Y, Yoneyama T, Hayashi Y et al. (2009) Effect of heat treatment on transformation temperatures and bending properties of nickel-titanium endodontic instruments. International Endodontic Journal 40, 247-53.

Zinelis S, Eliades T, Eliades G (2010) A metallurgical characterization of ten endodontic Ni-Ti instruments: assessing the clinical relevance of shape memory and superelastic properties of $\mathrm{Ni}-\mathrm{Ti}$ endodontic instruments. International Endodontic Journal 43, 125-34. 